\title{
Management, Supervision, and Leadership Principles and Skills: Implementation Is the Challenge
}

\section{By R. A. Milligan and K. C. McCuistion}

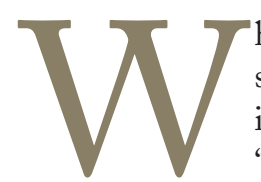

hen thinking about management, supervision, and leadership, common comments include these: "This is not rocket science." "It seems easy." "This is just common sense." And "I can learn this from experience." Given these statements, it should be easy to be an outstanding supervisor, manager, or leader. Obviously (and unfortunately) this is not the case. Great managers, supervisors, and leaders are rare, and in most cases they have worked very hard to become outstanding.

In this article, we articulate the difficulty of implementing the principles and skills required to be an exceptional leader, manager, or supervisor and focus on key principles and skills required to enhance interpersonal relationships and to become a better supervisor and coach. To narrow the discussion, the focus will be on supervision.

Although supervision seems like it should be easy, implementation of the necessary skills, principles, and processes to be a great supervisor do not come naturally for most of us. Rather, to become successful managers, supervisors, and leaders, we must change the way we think and change the way we behave and act.

\section{Changing the Way We Think}

Until the Industrial Revolution in the mid-1800s, supervision as seen in today's workforce did not exist. During the following century, the "control-focused" approach to supervision evolved primarily from managers doing what came naturally, given the circumstances, thinking, and expectations of the times. As a result of this evolution, the following conditions have emerged:

- Employees are viewed as costs.

- The primary function of the supervisor is to tell employees what to do-to be a boss.
- The primary expectation of employees is to comply with what they are told.

- Supervision is primarily reactive.

Over the last fifty or more years, originating from Dr Deming and the total quality management movement, research has verified that there is a far superior approach to supervising employees. ${ }^{1,2,3}$ This approach, called "quality focus," sounds nice, appears easy to implement, and has proven to enhance workforce productivity. It has, however, proven to be unnatural for most supervisors. This approach has the following characteristics:

- Employees are viewed as assets.

- The primary supervisory role is to direct, teach, support, and encourage the employee to attain great performance and high job satisfaction - to be a coach.

- Employees respond to actions from the supervisor that are fair and develop trust-the supervisor/employee relationship is an interpersonal relationship.

- Effective supervisors are proactive in developing relationships with employees and addressing workplace issues.

Table 1 contains a more detailed contrast of the two approaches.

Since most supervisors have very little training in supervision, they use their natural instincts in supervising employees. Today this default approach typically falls somewhere between the control-focused and quality-focused approaches; however, in most cases it is closer to the control-focused approach because two key aspects of the quality-focused approach are "unnatural" for most of us.

First, since labor cost is listed as an expense on the income statement and not as an asset on the balance sheet, it is difficult to view employees as assets rather than costs. Investing the time required to build a trusting relationship and the training and development to best utilize the talents 


\begin{tabular}{|c|c|c|}
\hline & Control-focused & Quality-focused \\
\hline \multirow{2}{*}{ Employee roles } & Take orders & Ask questions \\
\hline & Do your job & Critical part of a system \\
\hline \multirow{3}{*}{ Supervisors } & Give orders & Lead, "chalk the field," and coach \\
\hline & \multirow{2}{*}{ Use formal power } & Use informal power \\
\hline & & Build on strengths \\
\hline Mechanism for achievement & Do the job "right" & Exceed expectations \\
\hline \multirow{3}{*}{ Emphasis } & Means and/or tasks & Ends and/or accomplishments \\
\hline & Reactive & Proactive \\
\hline & Correcting problems & Quality \\
\hline \multirow{3}{*}{ Development of people } & Managers responsible for improvement & Everyone responsible for improvements \\
\hline & Focus on "correcting" weaknesses & Focus on building on strengths \\
\hline & Little need for training & Training essential \\
\hline Biggest fear & Upsetting the boss & Not meeting performance expectations \\
\hline \multirow{2}{*}{ Structure } & Bureaucratic & \multirow{2}{*}{ Inherently team oriented } \\
\hline & Inherently adversarial & \\
\hline Employees' response & Demotivating & Motivating \\
\hline Productivity & Less than the potential & Outstanding when successful \\
\hline
\end{tabular}

of each employee sound great, but they are difficult to execute. Second, our natural approach to supervision is to solve problems as they occur; however, not unlike our work with livestock and crops, the greatest supervision successes come from preventing problems and solving problems before they grow.

This proactive approach to problem solving and providing feedback is not natural for most supervisors. In order to more effectively view employees as assets and yourself as a coach, three skills are helpful: enhanced listening, high-quality feedback, and understanding how individuals respond to change.

\section{Enhanced Listening}

Think of a recent time when someone (employee, colleague, family member, or friend) was not listening when you had something important to say. How did you feel? Typical feelings in such a situation are frustration, anger, and disappointment. Unfortunately, most people are not great listeners and too often leave others with the above emotions when they do not listen effectively. To become a better listener, we need to practice active or empathic listening. Active listening should involve these elements:

- Listening to content and to emotional aspects and providing feedback on both

- Focusing on both message content and underlying feelings

- Focusing on joint problem solving

- Fostering open communication and employee development
To assist you in evaluating your listening, think about these four levels of listening:

1 Paying little or no attention

2. Listening, but also thinking about other things

3. Listening, but also thinking about how to respond to what is being said

4. Listening with nothing else in mind. Only after the person has finished speaking, think about how to respond

Most of us consider level three to be effective listening. However, when we are thinking about how to respond, we are not focusing exclusively on what is being said. Use the four levels to answer two questions. First, what proportion of the time is my listening in each of the four levels? Second, what should my goal be for using level four to improve my listening?

\section{Quality Feedback}

Providing a large amount of high-quality feedback is the backbone of great coaching. Unfortunately, the traditional view of feedback as positive or negative is inadequate. As Figure 1 illustrates, problems occur when a behavior is inappropriate or performance unacceptable. There are two very different possible causes: the situation or the person's behavior. The two causes require different forms of feedback; thus there is a need for three types of feedback: positive, redirective, or negative. ${ }^{4}$

Ranch managers, like managers of other businesses, are focused on detecting and correcting problems. That has 


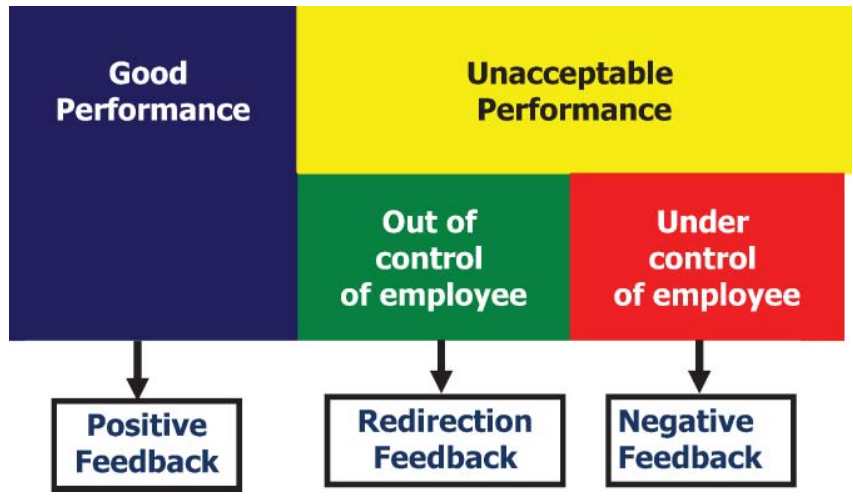

Figure 1. The three types of quality feedback.

traditionally been their job. The focus is on what is going wrong, and this focus is necessary. However, when providing feedback, the focus must be expanded to observe what people are doing well, as this serves as the basis of positive feedback. Great strides can be made in coaching employees with high-quality, positive feedback.

It is important to distinguish between redirection and negative feedback when performance or behavioral expectations are not being met. The key to great feedback is providing feedback that is appropriate to the performance. Appropriate means the feedback must correctly communicate the supervisor's assessment of the employee's performance. It is difficult to provide appropriate feedback when expectations are not met or when performance is "unsuccessful." A critical choice between redirection and negative feedback must be made.

Consider the following two scenarios where an employee failed to correctly complete a checklist of actions in the expected period of time:

1. Several of the tasks on the list are relatively new to the employee, and several unusual situations were present. Evidence indicates that the employee made every effort to succeed.

2. The employee is experienced in all of the actions on the list, and no unusual situations were present.

Now examine the two scenarios to determine the reason for the "unsuccessful" performance. In scenario one, the failure to complete the list can be explained by the situationthe context of the performance. The employee was not yet sufficiently skilled at some of the tasks, and there were some unusual circumstances. In scenario two, the failure to complete the list cannot be explained by the situation. The failure to complete the list can only be explained by the personal characteristics of the employee. He or she did not have sufficient motivation to complete the task, or he or she did not concentrate sufficiently to complete the actions on time.

In the first scenario, where failure to perform was caused by the situation or the context of the performance, choose to use redirection feedback. Redirection feedback communicates several things: First, the performance, in this case the failure to complete the checklist, is not acceptable and second, the individual is not at fault. It is crucial that the employee not feel that he or she is being punished. The supervisor is working with them to enable them to attain "successful" performance. Finally, changes are required in the situation to enable "successful" performance. Training and coaching are usually required. Sometimes the definition of "successful" performance must be adjusted because the original goal was not attainable. In this case, the employee should be trained and coached to master the required skills and should learn approaches to handle the unusual situations.

Redirection feedback is difficult. The supervisor needs to communicate that the performance was not acceptable but that the employee's personal characteristics are not at fault. Asking questions that enable the employee to recognize both that the performance was not acceptable and that the situation caused the lack of success often works best. Positive feedback on the appropriate attitudes and specific actions that were completed successfully is an important part of redirection feedback. The supervisor must also provide the training and coaching required for the employee to succeed.

The second scenario, in which the situation cannot explain the failure, calls for a very different response. Here the failure to perform is explained by the employee's personal characteristics-levels of commitment, motivation, concentration, and/or effort. In this scenario, negative feedback is necessary. Whether in the form of a reminder, reprimand, absence of positive feedback, or punishment, the negative feedback must have a significant impact on the employee in order to cause a change in behavior that will result in "successful" performance.

The challenge is making the right choice of feedback type. In this case, the wrong choice of providing negative feedback when redirection is the right choice is both common and potentially disastrous. Think of a recent example when someone blamed you personally (i.e., you were provided negative feedback) when you felt the culprit was the situation or context (i.e., you should have been provided redirection). How did you feel? You were probably upset, frustrated, or angry. Why does this scenario evoke such a strong reaction? The answer is that we believe we have been treated unfairly. A perception of fairness is one of, and perhaps the most important, ingredients in building trust in any relationship. Anytime feelings of unfairness appear the relationship is damaged.

There is a strong possibility that many supervisoremployee problems are a result of the supervisor's use of negative feedback when the employee perceived that redirection was in order. What should the supervisor do? The answer is twofold. First, any supervisor should be very careful in the use of negative feedback. Use redirection if 


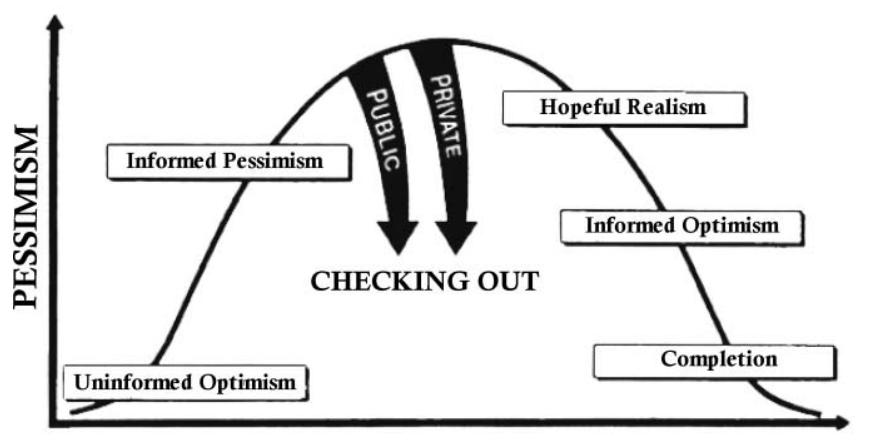

TIME

Figure 2. A typical response when change is viewed as an opportunity (adapted from Conner 1992). ${ }^{7}$

there is any possibility that the situation may be the cause of the "unsuccessful" performance. Second, when delivering negative feedback, be sensitive to the likelihood that the employee may be clinging to the idea that the situation is the culprit, so take time to clarify why the situation is not the cause of the performance failure.

\section{How Individuals Respond to Change}

In addition to effective listening and providing appropriate feedback, the third factor in becoming a better coach or supervisor is in understanding how individuals respond to change. Although humans have a myriad of emotional reactions to change, research verifies that we follow one of two patterns of behavior following any change in our personal or work life. We follow one pattern when we view the change as an opportunity and a second pattern when we view the change as a loss.

The pattern followed when the change is perceived to be an opportunity is found in Figure 2. The key to this pattern is the level of pessimism associated with the change. When people plan a change in their personal or work lives, they do some investigation into the alternatives. Despite this information seeking, they still enter the change with "uninformed optimism," meaning they do not know exactly how the change will affect their lives but they have a positive outlook on the situation. As people put the change in place, they move to "informed pessimism." They begin to experience the actual costs of making the change. Then they begin to doubt the decision to change and question whether this change is what they actually want to do. As long as they continue to view the change as opportunity, they are following the pattern in Figure 2.

During informed pessimism, the likelihood of "checking out" is highest. "Checking out" means that the individual no longer views the change as an opportunity. In fact, he or she now views the change as a loss. Importantly, informed pessimism is an inevitable part of change as opportunity; checking out is not. It is important for managers to facilitate discussions of doubts and of actual impacts of the change and to implement needed adjustments to reduce the

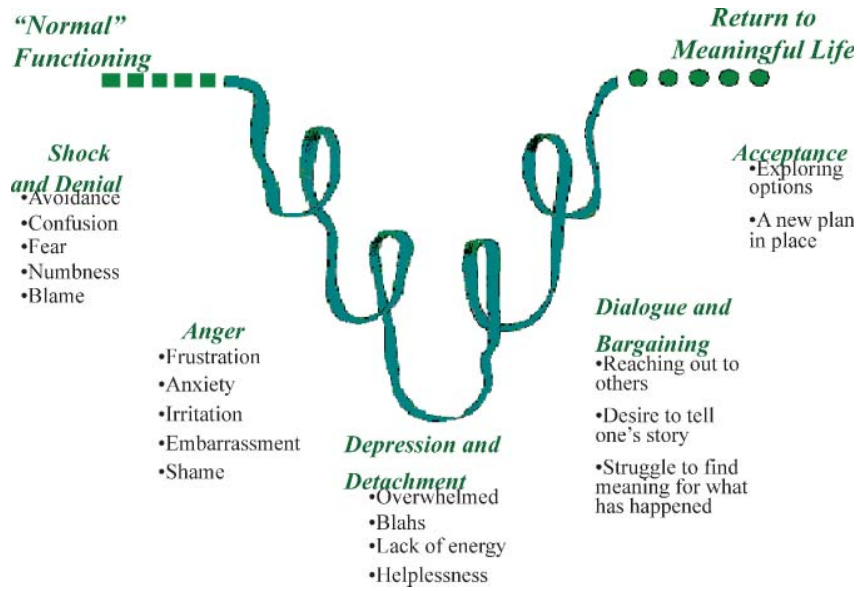

Figure 3. Stages of the grief cycle when change is viewed as a loss (adapted from Kubler-Ross 1969). ${ }^{5}$

likelihood of "checking out." With time, those who do not check out will move to the "hopeful realism" phase and will eventually complete the pattern.

When people view a change as a loss, not an opportunity, they go through a pattern that was first developed for the grieving process. ${ }^{5}$ There are several stages people go through in such a case (Fig. 3). Further research, however, has shown this pattern is followed for all change viewed as loss. The intensity of the emotional response and behavior is, of course, usually less.

The first stage of the pattern is shock and denial. Fear, confusion, and a general numbness characterize this stage. People often blame others in this stage for what is occurring. Anxiety, irritation, frustration, and shame characterize the next stage of the grief and loss cycle, usually identified as the anger stage. The next stage (depression or detachment) is an overwhelming sense of the "blues" and a general lack of energy. This stage is often accompanied by a feeling of helplessness. People in this stage have difficulty finding the energy to make decisions on their own. They often need the help of others to do so. People do not go through these stages of grief in a neat step-by-step fashion. They may flip back into an earlier stage. How quickly one goes through the pattern depends on the intensity of meaning that a person has placed on the change.

As people progress through the loss cycle, they become more open to alternatives when they enter the dialogue and bargaining stages. They have a desire to tell their story because they are struggling to find meaning for what has happened. As they enter the acceptance stage, they become more open to exploring options and to developing a new plan of action. Entering the acceptance stage does not mean that people like the change, but they begin to incorporate it into their lives. At the end of this last stage, people are empowered to make decisions because they have meaning in their life again. However, things are not exactly the same as they were prior to the time of the change. 


\section{Changing the Way We Behave as Supervisors}

While difficult, becoming a more effective supervisor by changing our thought processes in order to recognize employees as assets is actually the easy part. The difficult part is implementing the quality-focused approach because, to do so, we have to change our behavior as supervisors. Think about someone who has decided to eat more healthily or to get into an exercise routine. They too have had to change the way they behave, and in most cases it has been extremely difficult. Changing behavior as supervisors has much of the same difficulties - and similarly, very positive results.

To be a quality-focused supervisor, keep in mind that increased trust and respect must be the foundation of the enhanced relationship that is being developed between the employee and supervisor. ${ }^{6}$ The key to increased trust is fairness. Keep fairness in mind when making supervisory and coaching decisions. Also, remember that fairness is NOT “just being nice." For example, refraining from using redirection or negative feedback when it is needed may seem "nice," but it is not fair.

\section{Supervision Can Be Learned}

Although learning to be a better supervisor, manager, and leader is not easy, it is possible. It takes knowledge and, most importantly, practice. Positive results can be achieved when changes in management styles are made.

\section{References}

1. Blanchard, K. H., and S. M. Bowles. 1998. Gung ho!: turn on the people in any organization. New York, NY, USA: Morrow and Co. $187 \mathrm{p}$.

2. Buckingham, M., and C. Coffman. 1999. First, break all the rules: what the world's greatest managers do differently. New York, NY, USA: Simon \& Schuster. 271 p.

3. Milligan, R. A., And T. R. Maloney. 1995. Human resource management for golf course superintendents. Hoboken, NJ, USA: John Wiley \& Sons. 184 p.

4. Blanchard, K. H., And D. Shula. 1995. Everyone's a coach: you can inspire anyone to be a winner. New York, NY, USA: Harper Business. 197 p.

5. Kubler-Ross, E. 1969. On death and dying. New York, NY, USA: Scribner. 296 p.

6. Cover, S. R. 1989. The seven habits of highly effective people. New York, NY, USA: Simon \& Schuster. 139 p.

7. Conner, D. 1992. Managing at the speed of change: how resilient managers succeed and prosper where others fail. New York, NY, USA: Villard Books. 282 p.

Authors are Senior Consultant, Dairy Strategies LLC, Bruce, WY 54819, USA, and Professor Emeritus, Cornell University, Ithaca, NY 14853, USA (Milligan); and Assistant Professor, King Ranch Institute for Ranch Management, Texas A E'M University-Kingsville, Kingsville, TX 78363, USA, kim. mccuistion@tamuk.edu (McCuistion). 